\title{
miRNA-1246 in Extracellular Vesicles Secreted from Metastatic Tumor Induces Drug Resistance in Tumor Endothelial Cells
}

\section{Chisaho Torii}

Hokkaido Daigaku

Nako Maishi

Hokkaido Daigaku

Taisuke Kawamoto

Hokkaido Daigaku

Masahiro Morimoto

Hokkaido Daigaku

Kosuke Akiyama

Hokkaido Daigaku

Yusuke Yoshioka

Tokyo Ika Daigaku

Takashi Minami

Kumamoto Daigaku

Takuya Tsumita

Hokkaido Daigaku

Mohammad Towfik Alam

Hokkaido Daigaku

Takahiro Ochiya

Tokyo Ika Daigaku

Yasuhiro Hida

Hokkaido Daigaku

Kyoko Hida ( $\square$ khida@den.hokudai.ac.jp )

Department of Vascular Biology, Hokkaido University Graduate School of Dental 10 Medicine, Sapporo 060-8586, Japan 112 Vascular Biology, Frontier Research Unit, Institute for Genetic Medicine, Hokkaido 12 University, Sapporo 060-0815, Japan

\section{Research}

Keywords: Tumor endothelial cells, Drug resistance, miRNA, IL-6, Extracellular vesicle 
Posted Date: September 8th, 2020

DOI: https://doi.org/10.21203/rs.3.rs-60198/v2

License: (9) This work is licensed under a Creative Commons Attribution 4.0 International License. Read Full License

Version of Record: A version of this preprint was published at Scientific Reports on July 5th, 2021. See the published version at https://doi.org/10.1038/s41598-021-92879-5. 
The authors have withdrawn this preprint from Research Square 